\title{
XVIII. A demonstrable, accurate, and at all times practicable method of adjusting Hadley's sextant so as to render the Back observation equally correct with the Fore observation; and to measure an angle of 150,160, or 170 degrees, as accurately as one of 30,40 , or 50 degrees. Communicated to the astronomer royal by letter dated Sept. 28, 1803
}

\section{Rev. Michael Ward}

To cite this article: Rev. Michael Ward (1804) XVIII. A demonstrable, accurate, and at all times practicable method of adjusting Hadley's sextant so as to render the Back observation equally correct with the Fore observation; and to measure an angle of 150, 160, or 170 degrees, as accurately as one of 30,40, or 50 degrees. Communicated to the astronomer royal by letter dated Sept. 28, 1803, Philosophical Magazine Series 1, 18:70, 123-127, DOI: $10.1080 / 14786440408676458$

To link to this article: http://dx.doi.org/10.1080/14786440408676458

Published online: 18 May 2009.

III Article views: 3
Submit your article to this journal 
3 , a cock which conveys the water by a pipe from the reservoir to nearly the bottom of the boiler.

4, a cock which stops the steam when the potatoe tubs are taken off.

5, a safety valve fixed upon the top of the boiler, loaded with a weight of about four pounds to a square inch.

6 , a cock fixed in the side of the boiler to ascertain when it contains a proper quantity of water.

7 , one of the potatoe tubs detached from its lead vessel: it is two feet high, twenty inches wide at the top and seventeen inches at the bottom; it will hold eleven stone of potatoes. The boiler will steam sufficiently the four tubs of potatoes in fifteen or twenty minutes time; and if the whole are not in use, the lead pipes of those not wanted may be plugged up. Each tub and cover is held down by four levers, and an iron ball at the end of each lever.

When the potatoes are sufficiently boiled by the steam, the crane $\mathrm{N}$ raises and removes the tubs from their places to the stone troughs $\mathrm{UU}$, a section of one of which is given: the potatoes are there bruised for use.

XVIII. A demonstrable, accurate, and at all Times practicable Method of adjusting HADLEY's Sextant so as to render the Back Olservation equally correct with the Fore Olservation; and to measure an Angle of 150, 160, or 170 Degrees, as accurately as one of 30,40 , or 50 Degrees. Communicated to the Astronomer Royal by Letter dated Sept. 28, 1803. By the Rev. Michand Ward, of Tamworth, Staffordshire.

$\mathrm{H}$

I Aving several years used a Hadley's octant by Dollond, of the common construction, to compute the time from the sun's double altitude, in order occasionally to examine the rate of going of a gridiron pendulum clock, I have often lost a number of observations from want of certain dependence on angles above $90^{\circ}$ : the same inconvenience attended all attempts at revising a table of parallaxes of stars above $45^{\circ}$ meridional altitude; and also all lunar distances above $90^{\circ}$ required a more extensive instrument. The one I have, howcver, being, from its tried accuracy, a great favourite, it became more an object with me to invent some mode of bringing this instrument to measure larger angles than $90^{\circ}$ than to purchase a more extensive one. Flattering myself that the subjoined experiments and observations 
will give, if not exactness, at least a demonstrable deviation within 15 seconds, I shall feel myself happy if what I communicate prove of service to others in its present state, or may give rise to any new ideas of improvement in the instrument itself.

It is a known principle in optics, that the angle of reflection is equal to the angle of incidence : hence the angle formed by $\mathrm{B}$ and $\mathrm{C}$ in fig. 1. (Plate III.) being greater than a right angle $B$ receiving a ray and transmitting it to $C$, the consequence from the above principles is, $\mathrm{AD}$ becomes greater than $\mathrm{AE} ; \mathrm{AE}$ being equal to the distance of the reflecting points in $B$ and $C$ in the second figure, $B$ and $C$ forming a right angle, $E$ and $D$ coincide in the third figure; $B$ and $C$ forming an angle less than a right angle, $A D$ becomes less than AE.

Let us now suppose the eye placed behind $G$ in fig. 4; so as to observe or bring the point $G$ upon $A$, and behind $H$ in the line $\mathrm{BH}$ let the flame of a candle be placed; it is evident that the ray $\mathrm{HB}$ from the flame will fall upon $B$, be reflected to $A$, and be again reflected by $A$ in the direction $\mathbf{A G}$, so as to be distinctly seen by the eye behind $\mathbf{G}$.

Unscrew the lever of the back observation glass, and, turning it round, adjust it like the fore observation glass : in this attempt it will be found necessary to remove the sight-vane to a new situation, which may be done by glueing a small bed of wood on the side at $Z$ to hold it *.

Having

- It may be useful here to remark, that in upwards of 1000 altitudes of the sun, taken with my instrument with the back observation glass, turned as here described, and the sight-vane in a bit of wood fastened to the side, and all the opening of the back observation glass covered by pasting paper over its surface, except a strip exactly as broad as the opening, and at right angles to it, I have found, upon taking any even number of double altitudes of the sun, with their correspondent times, that when the average was found it always accorded in time and altitude with the middle place; whereas, when I have tried the fore observation glass in the same manner, it was frequently subject to deviation, and very seldom would bear apportioning, when both occupied the middie of the column, Let an example, taken yesterday, testify to what I assert.

\begin{tabular}{|c|c|c|c|c|c|c|c|}
\hline 1804, February 13 & $\begin{array}{l}x \\
x \\
x\end{array}$ & $\begin{array}{l}14 \\
15 \\
15 \\
P\end{array}$ & $\begin{array}{r}15 \\
2 \\
40 \\
\text { lace }\end{array}$ & $\overline{\mathbf{A}}$ & $\begin{array}{r}33^{\circ} \\
34 \\
34 \\
\text { rerage. }\end{array}$ & $\begin{array}{c}51 ! \\
0 \\
6\end{array}$ & $\begin{array}{l}15 \\
30 \\
40\end{array}$ \\
\hline & $\begin{array}{l}x \\
x \\
x\end{array}$ & $\begin{array}{l}16 \\
17 \\
17\end{array}$ & $\begin{array}{r}14 \\
2 \\
39\end{array}$ & : & $\begin{array}{l}34 \\
34 \\
34\end{array}$ & $\begin{array}{l}11 \\
23 \\
26\end{array}$ & $\begin{array}{l}30 \\
30 \\
30\end{array}$ \\
\hline & 61 & 35 & 52 & - & 204 & 57 & 55 \\
\hline & $x$ & 15 & $5^{8}$ & - & 34 & 9 & 39 \\
\hline
\end{tabular}




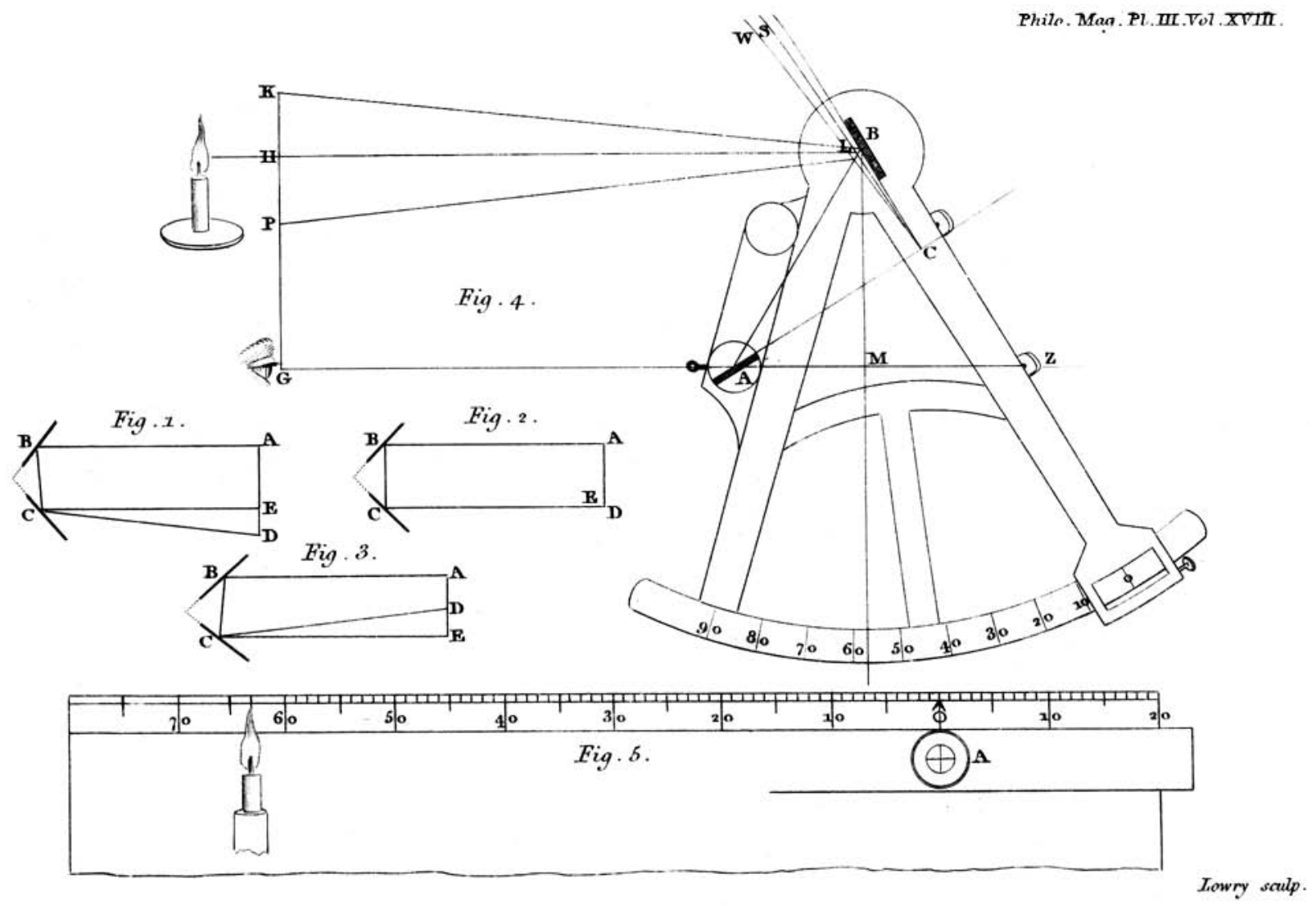


Having adjusted the back observation glass as for a fore observation, draw a pencil line from its centre to the centre of the hole in $Z$, and from the centre of the index glass let fall a perpendicular LM : this line in my instrument is 6.33333 inches.

Now GH being previously made equal to $\mathrm{LM}$, and the index set to zero on the limb, turn the back glass to its proper situation, and adjust it as nearly as you can.

The line GH is now to be changed for the following apparatus:- In a scale of wood (fig. 5.) about five inches broad, a foot long, and an inch thick, let there be a slit made * two or three inches long, and not exceeding 1-30th of an inch in breadth: at $\mathbf{6 . 3 3 3 3}$ inches from this slit let a scale of inches divided into tenths begin both ways; let a telescope, A, magnifying any number of times, from three or four to thirty, be so contrived as to move nearer or further from the slit by means of a screw, and also perpendicular to the plane of the scale; let the telescope also carry an index corresponding to the centre of the cross hairs within it; opposite to the slit let there be a socket to hold a small bit of candle. The whole will be easily comprehended by inspecting fig. 5 .

Fix both instrument and apparatus on a plank, or in a box open at both ends, so that GM may, for a reason to be given below, be $176 \cdot 88734$ inches.

If $G K$ exceeds $G H$, the angle $A C B$ is then more than a right angle, and the angle $\mathrm{KBH}$ is double the angle $\mathrm{SCB}$, for $\mathrm{SCA}$ is drawn to represent a right angle.

But if $\mathrm{GK}$ equals $\mathrm{GH}$, the angle $\mathrm{ACB}$ is a right angle; and $K$ and $H$ coinciding, the angle $K B H$ vanishes of course; $\mathrm{SCB}$ vanishes also, and coincides with the right angle SCA.

But if $\mathrm{GK}$ is less than $\mathrm{GH}$, so as that $\mathrm{K}$ fall on $\mathrm{P}$, then the angle AGB will fall within, or be included in the right angle $\mathrm{ACS}$, and the index line GB will take an angular situation similar to that of the line $\mathrm{CW}$, and the angle $\mathrm{P} B \mathrm{~B}$ will be double of the then angle $\mathrm{SCW}$.

The reason why $\mathrm{KBH}$ is double the angle $\mathrm{SCB}$ is : Suppose a ray comes from $G$ upon $A$, is thence reflected to $B$, the index glass $B$ being set at more than a right angle to

The inference is, that by increasing the distance of the two reflectors and the eye, and confining the observation to a square about one degree, or double the sun's diameter, in breadth, the accuracy is considerably increased.

* The slit falls behind the flame in the engraving. 
$\mathrm{AC}$, whatever excess in incidence $\mathrm{A}$ receives, the same excess in reflection also it transmits to $\mathrm{GK}$; of course, therefore, $\mathrm{KBH}$ is double $\mathrm{SCB}$.

The apparatus being thus explained, and the principles established, let us now apply them practically to measure the angle $\mathrm{KBH}$.

Let us first find the length of $\mathrm{BH}$ or GM.

From the property of the circle it is evident, that if the radius be 57.29578 inches, the sine of one degre will be one inch, and the sine and tangent of angles lesse than ten minutes have no discernible difference: therefore the sine may be used for the tangent: therefore 343.77468 inches radius will give six inches for one degree.

Now, six inches being divisible into sixty tenths, onetenth of an inch will correspond to one minute: but, as has been already observed, the angle $\mathrm{KBH}$ will measure double the angle SBC; therefore half the radius with the same six inches sine, will measure ont the minutes of the angle SBC at one-tenth of an inch for each minute.

Then 176.88734 inches must be the length of $\mathrm{BH}$ or GM.

If this length be doubled, then each tenth will measure thirty seconds.

If tripled, the divisions will be twenty seconds each, \&c. \&c.

Having placed the instrument, and directed the telescope along the line GM to $A$, light the candle and look for its reflection through the slit, and you will find three, five, or seven lines of light, but the middle one the brightest ; bring that into the centre of the telescope by screwing the telescope nearer to or further from the slit, as occasion may require: then note at what division the index on the telescope stands : suppose it at $4 \frac{1}{4}$ of the divisions to the right, the instrument will mcasure all angles by back observation $4^{\prime} 15^{\prime \prime}$ too much, yet subject to the laws of the back observation in the common way: thus an angle of $42^{\circ} 52^{\prime} 30^{\prime \prime}$ so taken, must be diminished to $49^{\circ} 48^{\prime} 15^{\prime \prime}$, and this taken from $180^{\circ}$ leaves $137^{\circ} 11^{\prime} 45^{\prime \prime}$, the true angle : and so in other cases.

If this mode be not approved of, another, perhaps as accurate, may be tried. Set the index of the telescope to 0 on the scale of the apparatus, and the index of the instrument at 0 on the limb; then move the index of the instrument along the limb till the middle bright light occupies the centre of the telescope as before; and the angle of devia- 
tion, if to the left, must be subtracted, if to the right, added: thus $4^{\prime} 15^{\prime \prime}$ in the example just given being to the right, must be added.

Many more, and perhaps useful observations, might be given, and a mode of setting both glasses perpendicular to the plane of the instrument by the use of the above apparatus; but I fear I have already exceeded the limits allowed to communications in a monthly publication, and shall therefore add no more-except to say, it will give me much pleasure to find the present communication considered as useful.

February, 14, 1804 .

XIX. On the Utility of the Oxygenated Muriatic Acid in the Cure of Scarlet Fever; with an easy Mode of preparing it for Medical Purposes. By Mr. Јонn Ay ReY Brathwatte, Member of the Royal College of Surgeons in London, and Surgeon to the Lancaster Dispensary*.

$\mathrm{H}$ Aving frequently experienced the inefficacy of the common mode of medical practice in the Scarlatina anginosa, I have been induced to make some inquiries into the nature, cause, and treatment of that disease, which has been prevalent in this town and neighbourhood for three years last past. The result of - my observations has been the discovery of a remedy in this disease, which is as much entitled to infallibility, as mercury in the lues, or bark in the ague: it is easily prepared, by any apothecary, of materials with which his shop is, or ought to be, always supplied; and requires no complex pharmaceutical apparatus with which those unaccustomed to practical chemistry are often liable, even from proper materials, to prepare chemical preparations totally different in their properties from those intended.

As I have no doubt but the contaginn of the scarlet fever produces an extraordinary degree of disoxygenation of the system, with great debility, and exhaustion of the sensorial power; I was led to suppose that oxygen, exhibited in some easy and pleasant manner, might not only destroy the contagious matter adhering to the tonsils, uvula, \&c., but, by penetrating the fine moist membrane of the lungs, and by chemical attraction uniting with the blood, excite the action

* Communicated by the Author. 